\title{
Neisseria Gonorrhoae and their antimicrobial susceptibility patterns among symptomatic patients from Gondar town, north West Ethiopia
}

\author{
Addisu Gize Yeshanew* and Rozina Ambachew Geremew
}

\begin{abstract}
Background: Neisseria gonorrhoeae, the causative agent of gonorrhoea, is a Gram negative, coffee-bean shaped facultative intracellular diplococcus bacterium, the classical sexually transmitted bacteria. Nowadays, N. gonorrhoeae has developed high-level resistance to all traditional antimicrobials used for the treatment of gonorrhoea and makes the treatment complicated. So, the aim of this study was to determine magnitude and antimicrobial resistance patterns of $\mathrm{N}$. gonorrhoeae.

Methods: A cross sectional study was conducted between April and August 2016 among STI clinic clients in Gondar town hospitals and health centers. Urethral swab and cervical swab specimens were inoculated to Thayer Martin media (OXOID, UK) plates. Observation of Gram-negative intracellular diplococcic was a presumptive diagnosis of gonococcal infection. Finally, antimicrobial susceptibility was assessed by using a modified Kirby-Bauer disk diffusion test, with results indicating susceptible, intermediate or resistant. Data were entered and analyzed using SPSS version 20.

Results: The overall prevalence of laboratory confirmed N. gonorrhoeae was 25(20.8\%). The isolated N. gonorrhoeae was resistant $100 \%$ to tetracycline, penicillin and $80 \%$ percent was multidrug resistant.

Conclusion: Prevalence and drug resistance of $\mathrm{N}$. gonorrhoeae were high in the study area. A large study is needed in order to know the magnitude in the community as well as to increase awareness of both regional health bureaus and the Ministry of Health about the treatment guide-lines.
\end{abstract}

Keywords: N. Gonorrhoeae, Antimicrobial sensitivity test

\section{Background}

Neisseria gonorrhoeae is a Gram negative, coffee-bean shaped intracellular diplococcus bacterium responsible for gonorrhoea which is one of the classical sexually transmitted infections (STIs) [1]. The causative organism is highly adapted to the genital tract and often causing asymptomatic and undetected infection [2]. Gonorrhoea is acquired by unsafe sex practices and also can be transmitted from mother to child during delivery [1], which has medically significant implications if not treated early.

\footnotetext{
* Correspondence: addisu.gize@sphmmc.edu.et; konjoaddisu@gmail.com Department of Microbiology, St. Paul's Hospital Millennium Medical College, Addis Ababa, Ethiopia
}

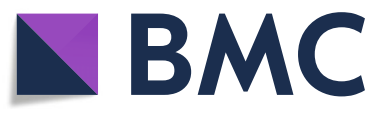

(c) The Author(s). 2018 Open Access This article is distributed under the terms of the Creative Commons Attribution 4.0 International License (http://creativecommons.org/licenses/by/4.0/), which permits unrestricted use, distribution, and

reproduction in any medium, provided you give appropriate credit to the original author(s) and the source, provide a link to the Creative Commons license, and indicate if changes were made. The Creative Commons Public Domain Dedication waiver (http://creativecommons.org/publicdomain/zero/1.0/) applies to the data made available in this article, unless otherwise stated.

Untreated gonorrhoea can lead infertility, inflammation leading to acute and chronic abdominal pain in women, ectopic pregnancy and maternal death, first trimester abortion, severe neonatal eye infection that lead to blindness, a fivefold increase in HIV transmission, disseminated gonococcal infection which results in localized septic arthritis, endocarditis, and meningitis $[1,3,4]$. Therefore, accurate efforts should be made to offer routine endocervical cultures for $N$. gonorrhoeae to all women who have risk behavior of STIs to prevent this infection [5]. Gonorrhoea treatment is complicated by N.gonorrhoeae's ability to develop antimicrobial resistance [6]. Since the introduction of antimicrobials to treat $N$. gonorrhoeae infection 70-80 years ago, $N$. gonorrhoeae 
has progressively developed resistance to most antimicrobial previously recommended for treatment, including sulfonamides, penicillin, tetracycline, and fluoroquinolone antibiotics [7]. In European Surveillance of combined antimicrobial susceptibility data, the resistance was found to be high to ciprofloxacin (30.9\%), penicillin (21.3\%) and tetracycline (59.8\%), and Neisseria gonorrhoeae strain (H041) that is highly resistant to the extended-spectrum cephalosporin (ESC) ceftriaxone [8, 9].

In many parts of the developing world, the absence of etiologic diagnostic capacity due to constraints imposed by cost, lack of equipment or trained personnel, and time management has forced health care providers to rely on a syndrome based approach to STI management, because many STIs have common symptoms or are asymptomatic and therefore undetected and untreated [10]. Therefore, this study primarily aimed to determine the prevalence $N$. gonorrhoeae and their antimicrobial susceptibility pattern among STI clinics attendants at Gondar town, North West of Ethiopia.

\section{Materials and methods}

A cross-sectional study was conducted from April 1 to August 30, 2016 in Gondar town hospitals and health centers, Gondar town, Northwest Ethiopia. The Town is $725 \mathrm{~km}$ away from Addis Ababa, Ethiopia, located in the North Gondar Zone of the Amhara Region. Based on figures from 2011 Central Statistical Agency (CSA) of Ethiopia, Gondar town has a total population of 207,044, of whom 98,120 are men and 108,924 women. There are two hospital (1 governmental and 1 private) and 5 health centers in the town.

Patients who visited Gondar town hospitals and health centers during the study period serve as the source population, whereas, all STI suspected patients attending in the STI clinic were included as the case of the study. However, patients under antibiotic treatment during 7 days before the enrolment and female patients who were on menstruation at the time of examination were excluded from the study. Descriptive statistics, including socio-demographics factors and known risk factors for STI were performed.

\section{Sample size and sampling technique}

Sample size was calculated based on the single population proportion formula considering the prevalence rate of $8.5 \%$ from the previous study conducted in Bahirdar, Northwest Ethiopia. Expected margin of error (d) was 0.05 and confidence interval $(\mathrm{z})$ was $95 \%$. One hundred twenty consecutive consenting patients, who attended Gondar town hospitals and health centers STI clinic, with one or more of the complaints as stated by WHO in its syndrome approach for the diagnosis of STI were included [5].

\section{Data collection procedure Socio-demographic characteristics}

After taking written informed consent from each study participant, a semi-structured questionnaire was used to collect socio-demographic and clinical data needed in this study. Data were collected by trained nurses.

\section{Sample collection \\ Urethral and cervical specimen}

External inspections of the genital area were made, and the characteristics of any local changes such as; erythema, abrasions, ulceration, urethral discharge and vaginal discharge were noted, including color, amount, odor and consistency. In the absence of visible urethral discharge, the patient was asked to milk the urethra. Specimens of discharge were obtained at or just within the urethral meatus for male and cervical swabs were taken for female. Two swabs were taken; one for Gram staining and the other were put on Amies transport media for $N$. gonorrhoeae culture at Gondar University Hospital laboratory. This laboratory, according to Ethiopian National Accreditation Office (ENAO), which established the Stepwise Laboratory (Quality) Improvement Process towards Accreditation (SLIPTA), has got 3 stars $(75-84 \%)$ ranked from 5 stars $(\geq 95 \%)$. ENAO gives recognition based on progress towards meeting requirements set by international standards and on laboratory performance during the 12 months preceding the SLIPTA audit, relying on complete and accurate data, to improve quality of public health laboratories in developing countries to achieve ISO 15189 standards.

\section{Laboratory method}

\section{Isolation and identification of N. Gonorrhoeae}

Identification was made by observing polymorphonuclear leucocytes (PMNLs) with Gram-negative intracellular diplococci as a presumptive diagnosis of gonococcal infection. Specimens inoculated directly into the modified Thayer Martin medium (MTM) (OXOID, UK) plates contained vancomycin, colistin, nistatin and trimetoprin and incubated at $36.5^{\circ} \mathrm{C}$ for $24-48 \mathrm{~h}$. Then isolates was identified as $N$. gonorrhoeae on the basis of colony morphology, Gram staining, oxidase test, and carbohydrate utilization test [11]. N. gonorrhoeae is observed as Gram negative diplococci when Gram stained, positive for oxidase, ferments only glucose, and is resistant to colisin [12].

\section{Antibiotic susceptibility testing}

From a pure culture, 3-5 selected colonies of bacteria were transferred to a tube with a straight wire and prepared in a suspension of $2.5 \mathrm{ml}$ normal saline and incubated at $36.5{ }^{\circ} \mathrm{C}$ until the turbidity of the suspension become adjusted to a McFarland 0.5. A sterile swab was used to distribute the bacteria evenly over the entire 
surface of MTM agar. The susceptibility to the following antimicrobial agents (OXOID, UK) were assessed: penicillin (P $10 \mathrm{IU}$ ), tetracycline (TE $30 \mu \mathrm{g}$ ), ciprofloxacin (CIP $5 \mu \mathrm{g}$ ), ceftriaxone (CRO $30 \mu \mathrm{g}$ ), Cefotaxime $(30 \mu \mathrm{g})$, Cefoxitin (FOX $30 \mu \mathrm{g}$ ), Clindmycin (CLI $2 \mu \mathrm{g}$ ). The criteria used to select the antimicrobial agents tested were based on their availability and frequent prescriptions for the management of gonococcal infection and the national list of medicines by Food, Medicine and Health- Care Administration and Control Authority (FMHACA) Ethiopia in 2010 to treat infections, and the syndromic management package for the management of sexually transmitted infections guideline from the Federal Ministry of Health.

Finally, antimicrobial susceptibility testing was performed for all isolates according to the criteria of Clinical and Laboratory Standard Institute (CLSI) by the modified Kirby-Bauer disk diffusion method on Thayer Martin medium plates, results as to susceptible or resistant were based on the M100-S24 Performance Standards for Antimicrobial Susceptibility Testing [12].

\section{Data quality control}

The questionnaire was pre-tested on 15 outpatient department patients for comprehensiveness, effectiveness, reliability and validity. Training was given for data collectors on data collection procedures with support from an investigator, venereologist and gynecologist. Culture media sterility was ensured by incubating $5 \%$ of each batch of the prepared media at $37^{\circ} \mathrm{c}$ for $24 \mathrm{~h}$. Performance of prepared media was also checked by inoculating with control strains N. gonorrhoeae ATCCTM 49226 (10) [13].

\section{Data analysis}

Data were entered and analyzed using SPSS version 20. Descriptive statistics was applied to determine the distribution of the socio-demographic and clinical characteristics.

\section{Ethical consideration}

The proposed study was approved by the research and ethics committee of the School of Biomedical and Laboratory Sciences of the University of Gondar. Official permission was obtained from each of the health facilities. The aim and details of the study was explained to each study participant before obtaining their written consent for specimen collection. Confidentiality was maintained at all levels of the study by using codes rather than names of the study participants. The results of all positive individuals were reported to the respective health facilities for better management of the patients.

\section{Results}

\section{Socio-demographic characteristics}

A total of 120 patients, 21 (17.5\%) males and 99 (82.5\%) females, were enrolled in the study. The mean \pm SD age of the study participants was $27.8 \pm 7.2$ years. The majority $(66.6 \%)$ of the study participants were in the age group below 30 years old. Fifty eight (48.3\%) were married. The majority of the patients 74 (61.7\%) were literate. Regarding their occupation, house wives numbered 26(21.7\%), and in terms of economic status, 37 (30.8\%) participants reported not to receiving income of their own (Table 1).

\section{Prevalence of N. Gonorrhoeae}

The overall prevalence of laboratory confirmed N. gonorrhoeae pathogens among suspected attendees of Gondar town hospitals and health centers was 25(20.8\%). N. gonorrhoeae infections were higher among females and age groups 15-29 yrs. The majority of the respondents 82(68.3\%) had multiple sexual partners, and 69(57.5\%) had never used condoms (Table 1).

\section{.Antimicrobial susceptibility pattern of N. Gonorrhoeae strains}

The antimicrobial susceptibility pattern of all isolates of $N$. gonorrhoeae is shown in Table 2. All isolates of $N$. gonorrhoeae showed resistance to at least one antimicrobial agent. The susceptibility pattern of isolates shows there were a hundred percent non-susceptibility for tetracycline, $76 \%$ non-susceptibility and $24 \%$ intermediate resistant for penicillin. The isolated $N$. gonorrhoeae was resistant $52 \%$ to ciprofloxacin, $48 \%$ to ceftriaxone, $44 \%$ to cefoxitin, $29 \%$ to cefotaxime, and $28 \%$ to clindmycin. Most of the isolates (80\%) showed multiple drug resistance and $11(44 \%)$ of the isolates showed non-susceptibility to both ciprofloxacin and ceftriaxone.

\section{Discussion}

The overall prevalence of laboratory confirmed N. gonorrhoeae was $25(20.8 \%)$. This prevalence rate was comparable with studies from Mozambique (22.5\%) [14], Egypt (26\%) [15] and southwestern Nigeria (25\%) [16]. However it was higher than the value reported from previous findings of studies done in Hawassa, Southern Ethiopia (5.1\%) [2] as well as the Northern part of Ethiopia [17]. Again the present finding was higher than the studies conducted in other countries: for example, $11 \%$ in Mongolia [18], 6\% United States [19], 1.4\% in Colombia [20], $6 \%$ in India and 1\% from Nigeria [21]. These discrepancies might be due to the lack of advancement in both early diagnosis and treatment in our country, which can lead to an increased number of untreated patients. A lack of differential diagnosis for resource poor settings can lead to an increased number of untreated patients 
Table 1 Prevalence of N. gonorrhoeae described by socio-demographic characteristics and known risk factors for STI, Gondar town, North West Ethiopia from April-August 2016

\begin{tabular}{|c|c|c|c|}
\hline Characteristics & Total N (\%), $n=120$ & N. gonorrhoeae + ve (\%),n=25 & $\begin{array}{l}\text { N. gonorrhoeae } \\
\text { - ve }(\%), n=95\end{array}$ \\
\hline \multicolumn{4}{|l|}{ Sex } \\
\hline Male & $21(17.5)$ & $6(29)$ & $15(71)$ \\
\hline Female & $99(82.5)$ & 19(19) & $80(81)$ \\
\hline \multicolumn{4}{|l|}{ Age } \\
\hline $15-29$ & $80(66.7)$ & $17(21)$ & 63(79) \\
\hline $30-45$ & $40(33,3)$ & $8(20)$ & $32(80)$ \\
\hline \multicolumn{4}{|l|}{ Marital status } \\
\hline Single & $62(51.7)$ & $14(23)$ & $48(77)$ \\
\hline Married & $58(48.3)$ & $11(19)$ & $47(81)$ \\
\hline \multicolumn{4}{|l|}{ Educational status } \\
\hline Illiterate & $46(38.3)$ & $9(20)$ & $37(80)$ \\
\hline Literate & $74(61.7)$ & $16(22)$ & $58(78)$ \\
\hline \multicolumn{4}{|l|}{ Occupation } \\
\hline Government employed & $31(25.8)$ & $7(23)$ & $24(77)$ \\
\hline House wife & $26(21.7)$ & $3(11)$ & 23(89) \\
\hline CSW & $11(9.2)$ & $2(18)$ & $9(82)$ \\
\hline No & 23(19.2) & $5(22)$ & 18(78) \\
\hline Self-employed & $29(24.1)$ & $8(18)$ & $21(72)$ \\
\hline \multicolumn{4}{|l|}{ Income } \\
\hline No & $37(30.8)$ & $7(19)$ & $30(81)$ \\
\hline$<800$ & 25(20.8) & $7(18)$ & $18(72)$ \\
\hline $801-1600$ & $31(25.8)$ & $5(16)$ & $26(84)$ \\
\hline$>1600$ & $27(22.5)$ & $6(22)$ & $21(78)$ \\
\hline \multicolumn{4}{|l|}{ Knowledge about STI } \\
\hline No & $54(45)$ & 10(19) & $44(81)$ \\
\hline Yes & $66(55)$ & $15(23)$ & $51(77)$ \\
\hline \multicolumn{4}{|l|}{ Alcohol use } \\
\hline No & $39(32.5)$ & $5(13)$ & $34(87)$ \\
\hline Yes & $81(67.5)$ & $20(25)$ & $61(75)$ \\
\hline \multicolumn{4}{|l|}{ Khat chewing } \\
\hline No & 102(86) & $21(21)$ & $81(79)$ \\
\hline Yes & 18(14) & $4(28)$ & $13(72)$ \\
\hline \multicolumn{4}{|l|}{ Smoking } \\
\hline No & $111(93)$ & $22(20)$ & $89(80)$ \\
\hline Yes & $9(7.5)$ & $3(33)$ & $6(67)$ \\
\hline \multicolumn{4}{|l|}{ History of abortion } \\
\hline No & $55(55.5)$ & $12(22)$ & $43(78)$ \\
\hline Yes & $44(44.5)$ & $7(15)$ & $37(84)$ \\
\hline \multicolumn{4}{|l|}{ Sexual partner } \\
\hline One partner & $38(31.6)$ & $7(18)$ & $31(82)$ \\
\hline More than one partner & $82(68.3)$ & $18(22)$ & $64(78)$ \\
\hline
\end{tabular}


Table 1 Prevalence of N. gonorrhoeae described by socio-demographic characteristics and known risk factors for STI, Gondar town, North West Ethiopia from April-August 2016 (Continued)

\begin{tabular}{|c|c|c|c|}
\hline Characteristics & Total N (\%), $n=120$ & N. gonorrhoeae + ve $(\%), n=25$ & $\begin{array}{l}\text { N. gonorrhoeae } \\
\text { - ve (\%), } n=95\end{array}$ \\
\hline \multicolumn{4}{|l|}{ Condom use } \\
\hline Never & $69(57.5)$ & 13(19) & $56(81)$ \\
\hline S/Rarely & $38(32)$ & $9(24)$ & 29(76) \\
\hline Always & 13(10.5) & $3(15)$ & $11(85)$ \\
\hline \multicolumn{4}{|c|}{ Males sexual contact with prostitute women } \\
\hline No & 16(13) & $1(6)$ & 15(94) \\
\hline S/Rarely & $100(83)$ & $21(21)$ & $79(79)$ \\
\hline Yes & $5(4)$ & $3(60)$ & $2(40)$ \\
\hline \multicolumn{4}{|l|}{ History of STI } \\
\hline No & $53(44.2)$ & $9(17)$ & $44(83)$ \\
\hline Yes & $67(55.8)$ & $16(24)$ & $51(76)$ \\
\hline \multicolumn{4}{|c|}{ Commonly using toillet \& washing materials } \\
\hline No & $81(67.5)$ & 19(23) & $62(77)$ \\
\hline Yes & $39(32.5)$ & $6(15)$ & $33(85)$ \\
\hline \multicolumn{4}{|c|}{ Contact new person the last 3 months } \\
\hline No & $78(65)$ & $16(21)$ & $62(79)$ \\
\hline Yes & $42(35)$ & $9(21)$ & $33(79)$ \\
\hline \multicolumn{4}{|l|}{ HIV status } \\
\hline Positive & $17(14.2)$ & $1(6)$ & 16(94) \\
\hline Negative & $103(86)$ & $24(23)$ & 79(77) \\
\hline
\end{tabular}

+ ve infected with N. gonorrhoeae, , ve non-infected with N. gonorrhoeae, S/Rarely sometimes or rarely, CSW Commercial Sex Workers, STI Sexual Transmitted Infection, HIV Human Immunodeficiency Virus

and a poor partner tracing system and using a syndromic approach, especially in the study area, might be the possible causes for this high prevalence rate.

The main reason for the rapid increase of $N$. gonorrhoeae resistance rates to Penicillin, Tetracycline and Ciprofloxacin after they had been recommended for clinical use is likely their indiscriminate use. Patients tend to administer antimicrobial treatment by themselves or visit non-formal medical institutions such as unregistered private clinics.

Table 2 Antimicrobial susceptibility pattern of N. gonorrhoeae isolates from STI clinic attendants in Gondar town, North West Ethiopia from April-May 2016

\begin{tabular}{llll}
\hline Antibiotic & $\# S(\%)$ & $\#$ I (\%) & \# R (\%) \\
\hline Penicillin & $0(0)$ & $6(24)$ & $19(76)$ \\
Tetracycline & $0(0)$ & $0(0)$ & $25(100)$ \\
Ciprofloxacin & $4(16)$ & $8(32)$ & $13(52)$ \\
Ceftriaxone & $13(52)$ & $*$ & $12(48)$ \\
Cefotaxime & $17(71)$ & $*$ & $7(29)$ \\
Cefoxitin & $14(56)$ & $*$ & $11(44)$ \\
Clindmycin & $18(72)$ & $*$ & $7(28)$ \\
\hline
\end{tabular}

\# $S$ number of sensitive, \# I number of intermediate, \# $R$ number of resistance, * have no intermediate range
Moreover, some patients do not complete the full treatment course, increasing the chance for antimicrobial resistance to develop. For example, patients could buy antimicrobials in drug stores without a prescription. Indeed, an association between self-prescribed antimicrobial use and gonococcal AMR may be high.

Gonococcal infection was observed in 6(29\%) of males and, patients having multiple sexual partners 18(22\%) and previous history of STI 16(24\%). This prevalence rate may be attributed to less condom usage by females and having a history of STI which leads to the infection. The same factors were shown to increase the exposure and prevalence rate of gonococcal infection in other studies as well [22, 23].

In addition, it was observed infection in both the age groups of 15-29 \& 30-45 years old. The finding on the target group was also supported by other studies [24, 25].

The antimicrobial resistance patterns ranged from $7(28 \%)$ for Cefotaxime and Clindmycin up to $100 \%$ in Tetracycline. This Tetracycline resistance pattern was similar with the study done in Gambella hospital, Ethiopia [1]. The present study showed a high level of resistance to Tetracycline $25(100 \%)$ and Ciprofloxacin 13(52\%) compared to the study done in North West 
Ethiopia (92.6, 40.9\%) (15), Southern Ethiopia (55, 18\%) [2] and United States $(25.3,19.2 \%)$ [4].

Most researchers are worried gonorrhoea will soon become untreatable with those antibiotics. This may be true in resource limited countries because of a lack of proper usage of antibiotics and application of antimicrobials as therapeutic agents for syndromatic treatment or may be due to the emergence of new resistant beta-lactamase producing strains over a period of time.

The resistance of Cefotaxime $7(28 \%)$ and Cefoxitin $11(44 \%)$ in the current study is also higher than the study conducted in Gambella hospital, Ethiopia [1] and Southern Ethiopia [2] but lower as compared to Tetracycline, Penicillin, Ciprofloxacin. The reason might be these drugs are expensive, not intensively used and not easily available outside the health institution, plus these drugs are newer compared to the others. Low resistance pattern of these drugs in our study may make these drugs excellent choices as first-line treatment.

\section{Conclusion}

High prevalence of $N$. gonorrhoeae and drug resistance among symptomatic clients who attended the STI clinics in the study area was observed. This should cause alarm and should lead to a large community based study and increased awareness of both regional health bureaus and the Ministry of Health about the treatment guide-lines.

\section{Abbreviations \\ AMR: Antimicrobial Resistance; CLSI: Clinical and Laboratory Standards Institute; ESBL: Extended-spectrum ß-lactamase; FDA: US Food and Drugs Administration; HIV: Human Immunodeficiency Virus; SPSS: Statistical Packages for Social Sciences.; STI: Sexually Transmitted Infections}

\section{Acknowledgements}

We acknowledge the staff of the STI clinics of Gondar town for their cooperation during data collection. We would like to thank Professor Moges Tiruneh and Dr. Kassahun Tameyalew for their advice and suggestions. Our acknowledgment also extends our manuscript grammatical and topographical editors, Meron Begashaw, Human Resource Strategies Fellow and last but not least we would like to acknowledge Amy Vercler, admin assistant of the SPHMMC for her language edition of the manuscripts.

\section{Funding}

This research work was financed by Amhara Regional Health Bureau, Ethiopia. The funder had no role in study design, data collection and analysis, decision to publish, or preparation of the manuscript.

\section{Availability of data and materials}

Data is available upon request.

\section{Authors' contributions}

AGY was involved in study conception, data analysis, drafting the manuscript and critically reviewing the manuscript. RAG was involved in the study conception and design, data analysis, and drafting the manuscript. Both authors have read, edited and approved the manuscript.

\section{Ethics approval and consent to participate}

The proposed study was approved by the research and ethics committee of the School of Biomedical and Laboratory Sciences of the University of
Gondar and official permission was obtained from each of the health facilities.

Consent for publication

Not applicable. This study does not contain any individual or personal data.

Competing interests

The authors declare that they have no competing interests.

\section{Publisher's Note}

Springer Nature remains neutral with regard to jurisdictional claims in published maps and institutional affiliations.

Received: 9 February 2018 Accepted: 6 July 2018

Published online: 17 July 2018

\section{References}

1. Ali S, Sewunet T, Sahlemariam Z, Kibru G. Neisseria gonorrhoeae among suspects of sexually transmitted infection in Gambella hospital, Ethiopia: risk factors and drug resistance. BMC Res Notes. 2016 Sep 13;9(1):439.

2. Hailemariam M, Abebe T, Mihret A, Lambiyo T. Prevalence of Neisseria gonorrhoeae. And their antimicrobial susceptibility patterns among symptomatic women attending gynecology outpatient department in Hawassa Referral Hospital, Hawassa, Ethiopia. Ethiop J Health Sci. 2013 Jan 1; 23(1):10-8.

3. Fingerhuth SM, Bonhoeffer S, Low N, Althaus CL. Antibiotic-resistant Neisseria gonorrhoeae spread faster with more treatment. Not More Sexual Partners PLoS Pathog. 2016 May; 12(5):e1005611.

4. Kirkcaldy RD, Harvey A, Papp JR, Del Rio C, Soge OO, Holmes KK, et al. Neisseria gonorrhoeae Antimicrobial Susceptibility Surveillance - The Gonococcal Isolate Surveillance Project, 27 Sites, United States, 2014. Morb Mortal Wkly Rep Surveill Summ Wash DC 2002. 2016 Jul 15;65(7):1-19.

5. Organization WH, others. Management of patients with sexually transmitted diseases: report of a WHO Study Group [meeting held in Geneva from 3 to 6 July 1990]. 1991 [cited 2016 Oct 31]; Available from: http://apps.who.int/ iris/handle/10665/40873

6. Organization WH. Global action plan to control the spread and impact of antimicrobial resistance in Neisseria gonorrhoeae. 2012 [cited 2016 Dec 28]; Available from: http://www.who.int/iris/handle/10665/44863

7. Kidd S, Moore PC, Kirkcaldy RD, Philip SS, Wiesenfeld HC, Papp JR, et al. Comparison of antimicrobial susceptibility of urogenital Neisseria gonorrhoeae isolates obtained from women and men. Sex Transm Dis. 2015 Aug;42(8):434-9.

8. Martin IMC, Hoffmann S, Ison CA. European surveillance of sexually transmitted infections (ESSTI): the first combined antimicrobial susceptibility data for Neisseria gonorrhoeae in Western Europe. J Antimicrob Chemother. 2006 Sep 1:58(3):587-93.

9. Ohnishi M, Golparian D, Shimuta K, Saika T, Hoshina S, Iwasaku K, et al. Is Neisseria gonorrhoeae initiating a future era of untreatable gonorrhea? detailed characterization of the first strain with high-level resistance to ceftriaxone. Antimicrob Agents Chemother. 2011 Jul 1;55(7):3538-45.

10. Verma R, Sood S. Gonorrhoea diagnostics: An update. Indian J Med Microbiol. 2016 Apr 1;34(2):139.

11. Juayang AC, Lim JPT, Acosido MAD, Jr DGM, Gallega CT. Antibiotic Susceptibility of Neisseria gonorrhoeae in Bacolod City, Philippines. Br Microbiol Res J [Internet]. 2015 [cited 2016 Oct 31];10(2). https://doi.org/10. 9734/BMRJ/2015/19641.

12. Wkler MA, Cockerill FR, Bush K, Dudely MN, Etiopoule GM, Hardy DJ, et al. Clinical and Laboratory Standard Institute. Performance standards for antimicrobial disc susceptibility tests; Approved standard, 10th edn. Available from: http://www.clsi.org/source/orders/free/ m02-a10.pdf.

13. Organization $\mathrm{WH}$, others. WHO global strategy for containment of antimicrobial resistance. 2001 [cited 2016 Dec 28]; Available from: http:// apps.who.int/iris/handle/10665/66860

14. Zimba TF, Apalata T, Sturm WA, Moodley P. Aetiology of sexually transmitted infections in Maputo. Mozambique J Infect Dev Ctries. 2010; 5(01):041-7.

15. Ali F, Aziz AA, Helmy MF, Mobdy AA, Darwish M. Prevalence of certain sexually transmitted diseases in Egypt. J Egypt Public Health Assoc. 1995; 71(5-6):553-75. 
16. Bersoff-Matcha SJ, Horgan MM, Fraser VJ, Mundy LM, Stoner BP. Sexually transmitted disease acquisition among women infected with human immunodeficiency virus type 1.J J Infect Dis. 1998;178(4):1174-7.

17. Tibebu M, Shibabaw A, Medhin G, Kassu A. Neisseria gonorrhoeae nonsusceptible to cephalosporins and quinolones in Northwest Ethiopia. BMC Infect Dis. 2013 Sep 5;13:415.

18. Garland SM, Tabrizi SN, Chen S, Byambaa C, Davaajav K. Prevalence of sexually transmitted infections (Neisseria gonorrhoeae, chlamydia trachomatis, trichomonas vaginalis and human papillomavirus) in female attendees of a sexually transmitted diseases clinic in Ulaanbaatar. Mongolia Infect Dis Obstet Gynecol. 2001;9(3):143-6.

19. Kent CK, Chaw JK, Wong W, Liska S, Gibson S, Hubbard G, et al. Prevalence of rectal, urethral, and pharyngeal chlamydia and gonorrhoeae. Detected in 2 clinical settings among men who have sex with men: San Francisco, California, 2003. Clin Infect Dis. 2005:41(1):67-74.

20. Ángel-Müller E, Rodríguez A, Núñez-Forero LM, Moyano LF, González P, Osorio $\mathrm{E}$, et al. The prevalence of and factors associated with $\mathrm{C}$. Trachomatis, N. Gonorrhoeae, t. Vaginalis, C. Albicans infection, syphilis, HIV and bacterial vaginosis in females suffering lower genital tract infection symptoms in three healthcare attention sites in Bogotá, Colombia, 2010. Rev Colomb Obstet Ginecol. 2012;63(1):14-24.

21. Okonko IO, Okerentugba PO, Adejuwon AO, Onoh CC. Prevalence of sexually transmitted infections (STIS) among attendees of lead city university medical Centre in Ibadan, southwestern. Nigeria Arch Appl Sci Res. 2012; 4(2):980-7.

22. Taffa N, Bjune G, Sundby J, Gaustad P, Alestrøm A. Prevalence of gonococcal and chlamydial infections and sexual risk behavior among youth in Addis Ababa. Ethiopia Sex Transm Dis. 2002;29(12):828-33.

23. Duncan ME, Reimann K, Tibaux G, Pelzer A, Mehari L, Lind I. Seroepidemiological study of gonorrhoea in Ethiopian women. 1. Prevalence and clinical significance. Genitourin Med. 1991;67(6):485-92.

24. Workowski KA, Berman SM. Centers for Disease Control and Prevention Sexually Transmitted Diseases Treatment Guidelines. Clin Infect Dis. 2007 Apr 1;Supplement_3(44):S73-6.

25. Force USPST. Screening for gonorrhoeae: recommendation statement. Ann Fam Med. 2005 May 1;3(3):263-7.

Ready to submit your research? Choose BMC and benefit from:

- fast, convenient online submission

- thorough peer review by experienced researchers in your field

- rapid publication on acceptance

- support for research data, including large and complex data types

- gold Open Access which fosters wider collaboration and increased citations

- maximum visibility for your research: over $100 \mathrm{M}$ website views per year

At $\mathrm{BMC}$, research is always in progress.

Learn more biomedcentral.com/submissions 